\title{
Study on Experiential Teaching of Product Design Based on Application-Oriented Talent Training
}

\author{
Chen Zhao ${ }^{1, *}$ \\ ${ }^{1}$ School of Fine Art and Design, Kunming University, Kunming, Yunnan 650000, China \\ *Corresponding author. Email: 244694782@qq.com
}

\begin{abstract}
Against the background of cultivating applied talents in local colleges and universities, product design major must build a bridge of exploration and innovation between classroom teaching and social practice, and realize the effective combination of design theory and design practice to cultivate professional talents required by social development. Targeted at the problems of students majoring in product design, such as weak practical ability, low innovation ability and weak knowledge transformation ability, this paper proposes to strengthen the link of experiential teaching in the course to improve students' practical ability, comprehensive innovation ability and communication and understanding ability. The value of product design can be realized, students' comprehensive ability can be improved and their practical ability can be cultivated through the experiential teaching, which is a teaching method that meets the needs of application-oriented undergraduate education. It is necessary to actively promote the innovation of teaching mode of product design major, focus on training application-oriented professionals, improve students' comprehensive innovation and practical ability, and constantly enhance the core competitiveness of product design major.
\end{abstract}

Keywords: Product design, Experiential teaching, Social practice.

\section{INTRODUCTION}

Cultivating innovative talents is an inevitable requirement for China's higher education reform and development in the 21 st century. And experiential teaching in colleges and universities is an effective way to cultivate innovative talents. This paper focuses on the "student-centered" "experiential" teaching model that stimulates students' desire for knowledge, improves learning efficiency, and enhances autonomous learning ability, in order to give full play to the role of practical courses in the professional knowledge structure, and cultivate students' innovative ability and practical problem-solving ability.

\section{REALIZING THE VALUE OF PRODUCT DESIGN IN EXPERIENTIAL TEACHING}

The value of product design lies in its continuous creation of new life styles for the society and human beings and bringing people the enjoyment of beauty through good experience of feeling the fun of the product, which delights people's spiritual world. The harmony between external beauty and internal beauty is the ultimate goal of product design, which also determines that product design is bound to be a discipline closely related to social activities. In experiential teaching, students can not only learn more solid professional knowledge, cultivate profound knowledge and theoretical literacy, but also develop skillful practical operation ability, which lays a solid foundation for the innovation of product design and better reflects the value of product design.

\subsection{The Ultimate Goal of Product Design Needs to Be Realized in Experiential Teaching}

Product design solves the relationship between people and people, people and things, and things and things, and helps solve various problems that people encounter in life. At the same time, it can delight people's spiritual world, change people's life style, improve people's life quality and happiness index. Its value evaluation standard is put forward 
by the society, tested by the market, and thus reflects its value. All these determine that product design is a very practical subject. That in turn determines the teaching objectives of product design major - taking product innovation as the core concept, based on the development of traditional culture and the times; adhering to the scientific law of product design centered on practice and application; taking cross-border collaboration as the approach, cultural creativity as the driving force, taking digital design as the means, industrial transformation and service as the key; and laying equal stress on design innovation and market application. Application-oriented product design talents should have keen observation, perception, insight, practical ability and creativity. Therefore, it is very necessary to understand the goal of product design for learning product design. Many students have insufficient understanding of the characteristics of product design major and lack of social awareness, which leads to slow update of professional knowledge, insufficient divergent thinking and poor communication skills. In the process of product design, these students pay too much attention to show the aesthetic taste of art, and the design concept often stays on the paper or in the selfsatisfied model, but they cannot really use product design to solve practical problems. Once their designs are put into actual production, there are many problems, not to mention entering the circulation link and standing the test of the market so as to realize the economic value of product design.

Someone once said: Art is me, design is others. Art is the promotion of the individuality of the selfspiritual realm, and its value evaluation criteria are not completely put forward by the society itself; whereas design is to solve the problem of the relationship between people and people, between people and things, and between things and things, whose value evaluation criteria are put forward by the society. Art and design are always mutually influenced and permeated. While improving students' aesthetic taste, product design education should also combine the experiential teaching mode of practicing with real problems and bring design tasks from the marketplace to the classroom. In the course of project-based teaching, the teaching content should be based on actual projects. When designing teaching content, teachers should integrate teaching resources and teaching objectives, do a good job in analyzing projects, setting elements and positioning themes, and skillfully transform the theoretical system of courses into products, so that students can have a more intuitive understanding and experience of the goals and characteristics of product design. In this way, students can better understand the basic theoretical knowledge of product design, and intuitively see the importance of learning basic knowledge and product transformation thinking process, and the transition period of their design thoughts can be shortened.

\subsection{The Exploration of Product Design Market Needs to Be Realized in Experiential Teaching}

The major of product design is a kind of practical art form combining function, artistry and economy. While displaying its artistic aesthetics, product design must solve practical problems and realize its market economic value through the specific functionality of the product. Economy is the foundation. Product design should serve for social economy, the development of which has a direct impact on the development of product design, which in return has a promoting effect on social economy. Due to the lack of practical experiential teaching, students have insufficient understanding of the society and market economy. As a result, some students cannot solve problems for enterprises, bring profits and meet the needs of the audience after entering social work. Enterprises generally believe that the students who have just graduated lack practical application ability, cannot quickly adapt to the needs of enterprise development, have weak hands-on practice ability, their product design lack of practical feasibility and their rational expression of product function and beauty is not in place. Therefore, it is very important to guide students to feel the relationship between society, market and economy and product design through experiential teaching.

Product design education should see the rapid development of the social status quo, realize that students only in the stage of theoretical research and design creativity are not able to fully meet the needs of the society for practical talents. The fierce competition in the market makes time and efficiency more important. Therefore, we should combine teaching activities with enterprises to carry out experiential teaching as soon as possible, and establish cross-teaching groups to ensure the teaching effect. Such education will be more direct and persuasive to the students. Thus, it can change students' learning concept, strengthen the purpose 
of professional learning, mobilize students' conscious initiative, promote the maturity of students' professional awareness and behavior, and lay a solid foundation for students to enter the society smoothly. Therefore, the development of product design not only needs a vibrant, healthy, dynamic and promising market, but also requires the improved school practice education, which is an important link as a strong support in product design to explore the market, in order to achieve its real value. Teachers should adjust and perfect the teaching plan according to the actual situation of enterprise development and the changes of market economy, so as to cultivate high-quality applied design talents to meet the needs of enterprises for product design talents. At the same time, it is also necessary to give teaching consideration to the marketing and markets of products, so as to better guide students to do a good job in design based on reality. It is necessary to pay attention to teaching students application-oriented knowledge, analyze and practice real product cases according to learning needs, and help them master the knowledge and skills they have learned through the intervention of enterprise teams in the teaching process, so as to achieve the teaching goal of cultivating their practical ability and innovation ability.

\section{THE COMPREHENSIVE ABILITY OF PRODUCT DESIGN CAN BE IMPROVED IN EXPERIENTIAL TEACHING}

Product design is a strong comprehensive, intersecting discipline, which involves many fields, including nature, science and technology, humanities, history and society. Therefore, product design education is also developing in the direction of diversification and multi-discipline. It is necessary to adjust measures to local conditions. The major is set up in accordance with China's national conditions, and develop with market demand, so as to enable students to integrate into the society to achieve the improvement of product design comprehensive ability.

\subsection{The Improvement of Innovation Ability}

Product design itself is about continuously conducting innovation activities to improve people's quality of life, so no innovation of the product will have no vitality. The ability of innovative thinking is an important part of the overall ability of human beings and an important pillar of the quality of well-structured thinking. Innovation ability is not only reflected in the learning and application of knowledge and the ability to innovate and invent new ideas and new technologies, but also a conscious behavior to pursue innovation. It is the ideological power to find problems and actively explore, and the strain ability to actively transform oneself and the environment. Therefore, product design education emphasizes the cultivation of students' innovation ability, and the cultivation of innovation, to a large extent, needs to combine with social practice to reflect its significance.

Traditional product design education pays more attention to the cultivation of aesthetic appreciation and the training of performance skills. While artistic expression, form shaping and theoretical research run through the whole process of education, the process of exploration and innovation in experiential teaching is lacked. In addition, the reform of teaching mode lags behind. The cramming method of teaching featuring "I lecture and you listen", "do what I tell you to do" and "I comment on what you do" and the phenomena of "routinized" teaching, "lack of communication" after class as well as "more watching and less doing" in practice, etc., seriously affect the cultivation of students' learning interest and independent learning initiative, and hinder the cultivation of creative thinking and practical ability emphasized in product design education. It is necessary to change the singularity and hysteresis of the traditional teaching mode by increasing the laboratory construction, and use experimental equipment and tools to conduct experiential teaching design, so as to better strengthen the interaction between teachers and students, form an exchange and learning atmosphere combining discussion and practice, and encourage students to participate in the experimental learning process unconsciously. This can also train students' ability of independent innovation, increase their professional and technical knowledge, open up ideas, strengthen exchanges and cooperation and guide students to explore and discuss problems from multiple perspectives and in a wide range of fields, so that they can find product design ideas in the real experience of design experiments, and enhance the power to seek knowledge. 


\subsection{The Improvement of Knowledge Integration Ability}

Product design is an interdisciplinary and marginal applied discipline based on multidisciplinary achievements. Students should not only master certain professional knowledge and skills, but also possess the quality of knowledgeable talents, which will lay a good foundation for them to participate in social competition and to conduct in-depth research and innovation in the professional field in the future.

The traditional educational framework restricts teachers and students to the inheritance of knowledge, and the idea of valuing knowledge over ability has been rooted in people's concept for a long time. As a result, students have a narrow range of knowledge and lack theoretical practice, so it is difficult for them to timely verify and develop and innovate the knowledge they have mastered. In the design process, they often feel that they are "exhausted in all their skills", and it is difficult for them to show their individuality and make innovations in product design, as too single knowledge structure hinders the expansion of design ideas. The experiential teaching can be carried out through the "non-genetic inheritors enter the classroom", to encourage students to experience the profound and extensive local culture, understand and integrate culture into product design. Through the transformation of traditional technology into modern product design concept and the use of intangible cultural heritage resources and traditional technology, students' comprehensive ability of product design can be improved, and the theoretical knowledge and practical teaching of product design can be designed. The students can apply the knowledge they have learned in the traditional process in a diversified way, which is conducive to the improvement of students' ability to apply what they have learned to the practical application, and to accelerate the process of the marketization of product design teaching results and the localization of local characteristics. Product design education should cultivate not only innovative talents, but also practical and versatile talents, that is, those who are not only proficient in their own professional knowledge, have a broad artistic vision, are involved in the knowledge of related disciplines, and have a strong interest in social and humanistic knowledge, so as to make the study of the whole product design major more integrated. From this perspective, the increase of product design teaching experience is very necessary, this will help to arouse students' learning enthusiasm, develop their ability of knowledge integration, and gradually cultivate applied talents with all-round qualities and innovative practical design abilities.

\subsection{The Improvement of Communication Skills}

Product design must also meet people's diverse physiological and psychological needs. Students need to understand the status quo of the social economy and the development trend of the whole society, so as to adapt to the continuous innovation requirements of the society for the art of design. In the future, product design will develop into a broader space. Design itself is a way of communication, and product design needs to be developed in communication.

Under the control of traditional knowledge education, teachers and students maintain a passive psychological state. All their efforts are aimed at better understanding and mastering the knowledge of textbooks, but they neglect the teaching interaction, lack the communication process in learning, and the practice of design language and communication methods. This makes the students lack of keen insight, extraordinary perception and good communication and cooperation ability in the design activities. They have unclear design purpose and vague design concept, and often "work behind closed doors" in their design process, so they are unable to communicate with customers and cooperate with team members effectively, and thus cannot achieve their design goals. The experiential teaching will enable students to face the product design task together and carry out the work mode of division of labor and collaboration through the team cooperation mode. It brings enterprise work situations in classroom teaching, help students establish good qualities, and exercise their ability to communicate with people, and understand the product design language, accurately communicate product design concepts to customers, companies and colleagues with design language, in order to achieve the consensus of all aspects and finally realize the value of the product design. Therefore, in the experiential teaching process, students are divided into groups according to the project content, students are made specific according to the project tasks, and students are guided to integrate the project tasks into the product design, so as to complete the implementation of the project tasks. The whole process of realizing product design task 
is usually carried out in groups to help students who are not interested in different directions, different specialties, different learning abilities and different cognitive abilities to promote each other, communicate with each other and inspire each other so as to improve teaching efficiency and teaching effect. Therefore, it is another goal of product design teaching to improve students' interpersonal communication ability, market analysis and judgment ability, professional control ability and social adaptability step by step by scientifically and rationally grouping.

\section{CONCLUSION}

It is necessary to realize that the traditional way of education has fallen behind the requirements of the times. With the rapid development of the society and the fierce competition in the industry, the society is in urgent need of "take and use" talents. Under the market economy, the industry has no enough time and patience to wait for students to grow up slowly after entering the society. Accelerating the "run-in period" has become the key for students to continue to engage in product design work. Therefore, importance should be attached to the teaching of product design in the practice of life and production. It is necessary to let students experience life, cultivate their ability to perceive life, find problems in practice, develop their potential, build and create an experiential learning environment centered on practice for them, improve students' hands-on ability, and strengthen students' understanding of product design. Attaching importance to the innovation and research of experiential teaching content in practical teaching links is very beneficial to the improvement of students' comprehensive application ability of product design. Only through the development of experiential teaching which bridges product design theory teaching and practical teaching grafting, can effective product design be applied to social life, so as to achieve the output of applied talents in experiential teaching practice.

\section{AUTHORS' CONTRIBUTIONS}

This article is independently completed by Chen Zhao.

\section{REFERENCES}

[1] Chen Hui. Research on "Project" Teaching and Practical Training of Product Packaging
Design Course [J]. Art Panorama, 2018(3). (in Chinese)

[2] Yang Hui. Exploration on the Path of Projectbased Teaching Reform of Product Design Course $[\mathrm{J}]$. Computer Products and Circulation, 2020.09. (in Chinese)

[3] Pan Lusheng. Essays in Design and Art Education [J], Shandong Pictorial Publishing House, 2005.07. (in Chinese)

[4] Li Chaode, Li Wenxiang. Rethinking on Art and Design $[\mathrm{J}]$. Journal of Soochow University, 2003-06-01. (in Chinese)

[5] Li Wenwen. Research on Applied Practice of Product Design Teaching in the Context of "Internet $+"[\mathrm{~J}]$. Journal of Puer University, 2020.06. (in Chinese)

[6] Jin Chengyu. Fregments of Product Design Teaching Practice $[\mathrm{J}]$. China Science and Technology Information, 2009.10. (in Chinese) 